Correspondence to: Dr Flegg. protein (gp120) in the viral envelope. ${ }^{4}$ During the first few weeks of treatment with zidovudine platelet counts rose in both patients with thrombocytopenia and those with normal counts. This suggests that reticuloendothelial inhibition may not be the only mechanism.

The eventual fall in platelet count with longer treatment probably had several causes, but the only significant association in our patients was with the development of probable myelotoxicity due to zidovudine, suggesting that this was the cause. We found no easily identifiable variables before treatment, other than a low platelet count, that predicted a good eventual response.

Current treatments for thrombocytopenia related to HIV infection have potential disadvantages - namely, immunosuppression from steroids and splenectomy with consequent risk of progression of the disease, problems of availability of high dose immunoglobulins, and lack of access to veins, especially in intravenous drug users. Zidovudine may be a useful alternative for symptomatic thrombocytopenia. The good response among those with even severe thrombocytopenia shows that this should not be considered a contraindication to treatment.

We acknowledge Lothian Health Board, the American Foundation for AIDS Research for financial support (PJF), and our colleagues Drs J A Gray and P D Welsby for access to results in their patients.

1 Hymes KB, Greene JB, Karpatkin S. The effect of azidothymidine on HIV related thrombocytopenia. $N$ Engl F Med 1988;318:516-7.

2 Swiss Group for Clinical Studies on the Acquired Immunodeficiency Syndrome. Zidovudine for the treatment of thrombocytopenia associated with human immunodeficiency virus (HIV). Ann Intern Med 1988;109:718-21.

3 Jaffe HS, Abrams DI, Amman AJ, et al. Complications of co-trimoxazole in treatment of AIDS associated Pneumocystis carinii pneumonia in homotreatment of AlDS 1983 ;i:1109-11.

4 Donahue RE, Johnson MM, Zon LI, Clark SC, Groopman JE. Suppression of in vitro haematopoiesis following human immunodeficiency virus infection. Nature 1987;326:200-3.

(Accepted 20 January 1989).

\section{Persistent increase in caffeine concentrations in people who stop smoking}

\section{Neal L Benowitz, Sharon M Hall, Gunnard Modin}

\section{Clinical Pharmacolog}

General Hospital Medical

Center; Departments of

Medicine and Psychiatry,

University of California,

San Francisco; and San

Francisco Veterans

Administration Medical

Center, California, United

States

Neal L Benowitz, MD,

professor of medicine and

psychiatry

Sharon M Hall, PHD, professor of medical psychology statistician

Correspondence to:

Professor N L Benowitz, San

Francisco General Hospital

Medical Center, Building

30, 5th Floor, 1001 Potrero

Avenue, San Francisco, CA

94110 , United States.

BrMed F 1989;298: 1075-6

Mean (SD) caffeine consumption and plasma caffeine and cotinine concentrations in subjects who had stopped smoking for 12 and 26 weeks and in those who continued smoking.

\begin{tabular}{|c|c|c|c|c|}
\hline & \multicolumn{4}{|c|}{ Values according to: } \\
\hline & \multicolumn{2}{|c|}{ Smoking state at 12 weeks } & \multicolumn{2}{|c|}{ Smoking state at 26 weeks } \\
\hline & Baseline & At 12 weeks & Baseline & At 26 weeks \\
\hline \multicolumn{5}{|l|}{ No of subjects: } \\
\hline Former smokers & \multirow{2}{*}{\multicolumn{2}{|c|}{$\begin{array}{l}34 \\
30\end{array}$}} & \multicolumn{2}{|c|}{24} \\
\hline Smokers & & & & \\
\hline \multicolumn{5}{|c|}{ Plasma caffeine $(\mu \mathrm{mol} / \mathrm{l}) \dagger$ : } \\
\hline Former smokers & $6.64(7.41)$ & $17.89(20.65)^{\star}$ & $7 \cdot 33(8 \cdot 39)$ & $19.54(16.06)^{\star}$ \\
\hline Smokers & $7 \cdot 69(10 \cdot 06)$ & $9 \cdot 39(8.74)$ & $7 \cdot 14(9 \cdot 12)$ & $7.05(6.74)$ \\
\hline \multicolumn{5}{|c|}{ Caffeine consumption $(\mathrm{mg} / \mathrm{kg} /$ day $)$ : } \\
\hline Former smokers & $2.05(1.66)$ & $1.94(1.68)$ & $2 \cdot 14(1.55)$ & $1.62(1 \cdot 11)^{\star}$ \\
\hline Smokers & $1.44(1.22)$ & $1.04(0.68)$ & $1 \cdot 36(1 \cdot 14)$ & $1.52(1.31)$ \\
\hline \multicolumn{5}{|c|}{ Plasma cotinine $(\mu \mathrm{mol} / \mathrm{l}) \dagger$ : } \\
\hline Former smokers & $1 \cdot 35(0 \cdot 61)$ & $0.01(0.03)^{\star}$ & $1 \cdot 25(0 \cdot 48)$ & $0(0.01)^{\star}$ \\
\hline Smokers & $1.66(0.66)$ & $1.03(0.84)^{\star}$ & $1.55(0.60)$ & $1.25(0.78)^{\star}$ \\
\hline
\end{tabular}

*Comparison of baseline value $v 12$ or 26 weeks, $\mathrm{p}<0.05$ ( $2 \times 2$ repeated measures analysis of variance).

tSamples collected between 1600 and 2000 .

Cigarette smokers on average drink more coffee than non-smokers and can metabolise caffeine much more rapidly. ${ }^{12}$ One possible explanation for their increased consumption is that smokers need to drink more coffee to achieve the desired concentrations of caffeine in the body and hence the desired effects. When smokers stop smoking the rate at which caffeine is metabolised declines. If consumption of caffeine remains the same concentrations of caffeine in the body should rise. Persistent increases in caffeine concentrations may cause concern in view of recent data showing an increased risk of coronary heart disease in and low birth weight of children of heavy coffee drinkers. ${ }^{34}$

We studied plasma caffeine concentrations and caffeine consumption before and for six months after subjects gave up smoking.

\section{Subjects, methods, and results}

Ninety five healthy subjects were recruited for a stop smoking programme. ${ }^{5}$ The subjects' average age was 38 (range 19-60); 38 were men, 87 were white, and almost all were middle or working class. Subjects were
Gunnard Modin, BS, research

BMJ VOLUME $298 \quad 22$ APRIL 1989 assessed before entry to the programme and 12 and 26 weeks afterwards. Assessment included analysis of plasma samples for cotinine (a primary metabolite of nicotine used to indicate nicotine intake) and caffeine concentrations, body weight, and a three day record of weighed food intake.

Sixty eight subjects completed the study. Data were available on 64 subjects at 12 weeks and 61 subjects at 26 weeks. The subjects who subsequently continued smoking were significantly older (mean $42.8 v 36.2$ years) but cigarette consumption, numbers of years of smoking, and plasma cotinine and caffeine concentrations were not significantly different between those who gave up and those who continued smoking. At 12 and 26 weeks plasma caffeine concentrations in subjects who stopped smoking were more than double the baseline value (table). Caffeine concentrations in smokers changed little throughout the study. Subjects who stopped smoking had significantly decreased their caffeine consumption at 26 weeks.

\section{Comment}

Our study confirms the hypotheses that plasma caffeine concentrations increase after people give up smoking and remain increased for at least six months. This increase was substantial, averaging more than $250 \%$. In subjects who continued to smoke caffeine concentrations were unchanged, as expected.

The average caffeine concentration in the body is determined by the consumption and rate of metabolism of caffeine. Consumption was either unchanged (at 12 weeks) or decreased (at 26 weeks) in subjects who stopped smoking. Thus the increased caffeine concentrations were the result of slowed metabolism due to abstinence from tobacco. Caffeine consumption was significantly decreased at 26 weeks, which is consistent with a degree of self regulation of caffeine concentrations. Regulation of caffeine concentrations could explain why cigarette smokers drink more coffee. As they metabolise caffeine more quickly, the half life of caffeine is shorter and the desired effects of the caffeine disappear or symptoms of withdrawal appear more quickly. Smokers would need to drink coffee more frequently to maintain caffeine concentrations similar to those in non-smokers. The rate of metabolism of caffeine decreases within three or four days after a subject stops smoking. Assuming that consumption of caffeine is unchanged, high caffeine concentrations could contribute to the tobacco withdrawl syndrome.

An increase of $250 \%$ in caffeine concentrations is 
equivalent to drinking two and a half times as many cups of coffee or tea each day as usual. If there is a dose response relation between coffee consumption and coronary heart disease or low birthweight babies, as seems to be the case, and that risk is mediated by caffeine then smokers who abstain would be at continuing high risk because of their caffeine consumption. Doctors offering antismoking treatment should advise patients that continued consumption of coffee at the same level may exacerbate the tobacco withdrawal syndrome and contribute to increased health risks; these patients should reduce their consumption.
This research was partly supported by grants from the National Institutes of Health.

I Istvan J, Matarazzo JD. Tobacco, alcohol, and caffeine use: a review of their interrelationships. Am Psychol Bull 1984;95:301-26.

2 Parsons WD, Neims AH. Effect of smoking on caffeine clearance. Clin Pharmacol Ther 1978;24:40-5.

3 LaCroix AZ, Mead LA, Liang K-Y, Thomas CB, Pearson TA. Coffee consumption and the incidence of coronary heart disease. $N$ Engl $f$ Med consumption and

4 Martin TR, Bracken MB. The association between low birth weight and caffeine consumption during pregnancy. Am J Epidemiol 1987;126:813-21. 5 Hall SM, McGee R, Tunstall CD, Duffy J, Benowitz NL. Changes in foo intake and activity after quitting smoking. $\mathcal{f}$ Consult Clin Psychol 1989;57 81-6.

(Accepted 25 fanuary 1989)

\section{Identifying hypoxaemia in children admitted for adenotonsillectomy}

\author{
V H van Someren, J Hibbert, J K Stothers, \\ M C Kyme, G A J Morrison
}

United Medical and Dental Schools of Guy's and St Thomas's Hospitals, Guy's Hospital, London SE1 9RT $\mathrm{V} H$ van Someren, $\mathrm{MD}$, lecturer in paediatrics J Hibbert, FRCS, consultant otorhinolaryngologist

\section{Joint Academic \\ Department of Child}

Health and Ear, Nose, and Throat Department, The London Hospital Medical College and The London Hospital, London E1 J K Stothers, $\mathrm{MB}$, senior lecturer, neonatal research group

M C Kyme, SEN, research nurse, neonatal research group G A J Morrison, FRCS, registrar

Correspondence to: Dr van Someren.

BrMed J 1989;298:1076 without recourse to studies during sleep.

\section{Subjects, methods, and results} for adenotonsillectomy.
Most children with obstructive sleep apnoea have adenotonsillar hypertrophy,,$^{1-3}$ but what proportion of the children with large tonsils and adenoids have obstructive sleep apnoea is unknown. ${ }^{45}$ We studied this and whether affected children might be identified

Forty four children (aged 2 to 7 ) were studied on the night before adenotonsillectomy. Twenty controls with no active symptoms of upper or lower respiratory tract disease were studied on the night before another elective procedure. Both groups underwent a preoperative clinical assessment by an otorhinolaryngologist, who noted symptoms, signs, and the indication

Oxygen saturation was measured continuously overnight with a pulse oximeter (Novametrix). Chest impedance was also measured and electrocardiography performed. The baseline oxygen saturation during sleep was obtained by sampling the saturation three times an hour outside dips. Dips in the saturation of $10 \%$ or more below the baseline value were studied. A stepped fall in saturation with steady pulse waveform and continued breathing movements suggested obstruction of the airways. These episodes were counted as incidents per hour and their length noted as
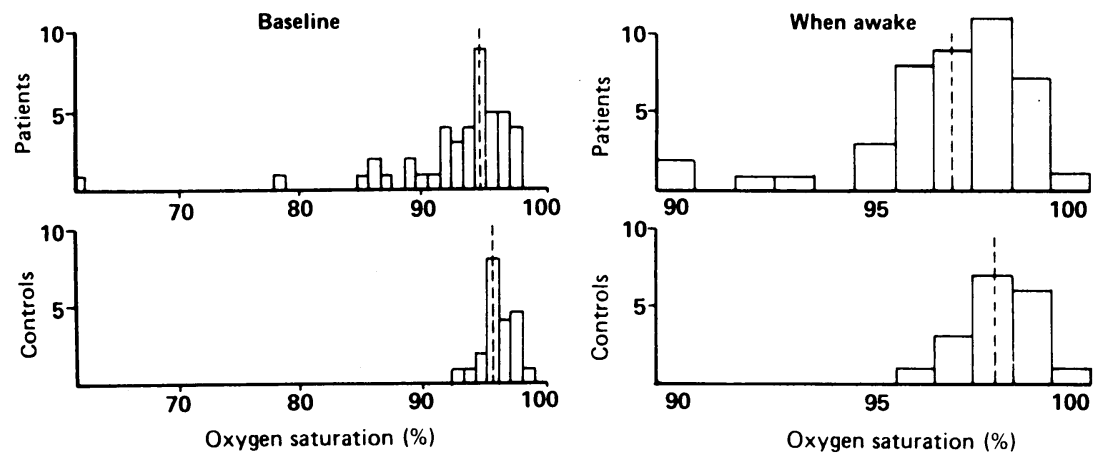

Results of monitoring oxygen saturation. Dashed lines show median values. Data are not normally distributed; for each measure the difference between patients and controls was highly significant (Mann-Whitney $U$ test; $p \leqslant 0.005$ ) time of hypoxia per hour. Oxygen saturation when the child was awake was noted at the beginning or end of the night.

The figure shows the full results of measuring oxygen saturation. For all measures of hypoxaemia a substantial minority of the patients admitted for adenotonsillectomy fell completely outside the normal range. Fifteen children who suffered night time hypoxaemia were identified, with baseline oxygen saturation below $90 \%$ (nine patients) or at least one hypoxic episode an hour (13), or both (seven). Twelve children had episodes of hypoxia (totalling $\geqslant 1$ minute per hour). The 15 children who suffered night time hypoxia were then compared with the remaining 29 from the group admitted for adenotonsillectomy.

There were no notable differences between the groups regarding sex, history of snoring or apnoea, body weight, or any features found on examination of ears, palate, mandible, tonsils, or neck glands. The clinical features that did distinguish the hypoxic group were younger age (median $3.5 v 5.6$ years; $\mathrm{p}<0.01$ ), non-white ethnic origin $(80 \%(12 / 15) v 24 \%(7 / 29)$ $\mathrm{p}=0.001$ ), and physical signs of nasal obstruction namely, open mouth and audible respiration at rest $(93 \%(14 / 15) v 38 \%(11 / 29) ; \mathrm{p}=0.001)$. In addition, oxygen saturation when the patient was awake was lower (median $95 \%$ v 97\%; $<<0.001$ ).

Hypoxic patients could not be identified by clinical features alone, but by combining the presence or absence of breathing through the mouth with the oxygen saturation when awake we identified affected patients with $93 \%$ sensitivity $(95 \%$ confidence interval 70 to $100 \%$ ) and $86 \%$ specificity ( 73 to $99 \%$ ).

\section{Comment}

We showed that significant night time hypoxaemia is common, occurring in $34 \%$ of children admitted for adenotonsillectomy. We have clearly defined the importance of breathing through the mouth as a clinical sign of obstruction and the usefulness of measuring oxygen saturation when awake. Children who clearly breath through the mouth will suffer night time hypoxaemia unless their oxygen saturation when awake is at least $\mathbf{9 7 \%}$. We hope that this will help paediatricians and otorhinolaryngologists to assess children correctly and avoid unnecessary operations.

1 Brouillette RT, Fernbach SK, Hunt CE. Obstructive sleep apnea in infants and children. F Pediatr 1982;100:31-40.

2 Guilleminault C, Eldridge FL, Simmons FB, Dement WC. Sleep apnea in eigh children. Pediatrics 1976;58:23-31

3 Mauer KW, Staats BA, Olsen KD. Upper airway obstruction and disordered nocturnal breathing in children. Mayo Clin Proc 1983;58:349-53.

4 Grundfast KM, Wittich DJ. Adenotonsillar hypertrophy and upper airway obstruction in evolutionary perspective. Laryngoscope 1982;92:650-5.

5 Maw AR. Tonsillectomy today. Arch Dis Child 1986;61:421-3.

(Accepted 20 fanuary 1989) 